\title{
Treatment of Idiopathic Pulmonary Fibrosis
}

\author{
Sherif T. Abuserewa ${ }^{1}$, Richard Duff ${ }^{2}$, Gregory Becker ${ }^{2}$ \\ 1. Internal Medicine, Grand Strand Regional Medical Center, Myrtle Beach, USA 2. Department of Pulmonary and \\ Critical Care Medicine, Grand Strand Medical Center, Myrtle Beach, USA
}

Corresponding author: Sherif T. Abuserewa,dr_sherif_tayceer@hotmail.com

\begin{abstract}
Idiopathic pulmonary fibrosis (IPF) is a chronic, progressive, fibrosing interstitial pneumonia of unknown cause, occurring in adults and limited to the lungs. In the past, treatment was aimed at minimizing inflammation and slowing the progression of inflammation to fibrosis. However, the underlying lesion in IPF may be more fibrotic than inflammatory, explaining why few patients respond to anti-inflammatory therapies and the prognosis remains poor.
\end{abstract}

In this review of literature, we will be focusing on main lines of treatment including current medications, supportive care, lung transplantation evaluation, and potential future strategies of treatment.

Categories: Internal Medicine, Pulmonology, Other

Keywords: ipf, progressive interstitial lung disease, pulmonary disease, literature review of disease, future management

\section{Introduction And Background}

Idiopathic pulmonary fibrosis (IPF) treatment plan depends on the disease prognosis, severity, and the patient's wishes. IPF treatment can be challenging as the disease course is unpredictable where some patients develop episodes of exacerbations after a period of stability, and the actual range of survival of these patients is highly variable where $20 \%-25 \%$ of patients' survival may exceed 10 years [1-4]. Moreover, patients with IPF are usually older in age and have comorbidities such as chronic obstructive pulmonary disease (COPD) and heart failure, which may worsen their IPF symptoms. Treating physicians can have difficulty in figuring out if patients' functional limitations are the result of disease progression, comorbidities, deconditioning, or simply the aging process.

\section{Review}

\section{Disease severity and prognosis}

The gender-age-physiology (GAP) model is the most commonly used and validated clinical prediction model that can predict 1, 2, and 3 years of mortality risk [5], and thus it is a good estimate of patient's prognosis that can be included with the patient's disease severity in the physician-patient discussion about available treatment options either medically or surgically such as lung transplantation or palliative care. Furthermore, the prognosis is reassessed along the disease course clinically by the occurrence of exacerbations or worsening of symptoms and by pulmonary function test assessment every three to six months. If there is a significant decline in pulmonary function, the available treatment options may change $[6,7]$. Recently, some blood and genomic markers can find their way as prognostic factors in IPF patients. Blood markers include proteins reflecting alveolar epithelial cell injury or activation of fibrotic pathways [8] including periostin, fibulin-1, collagen degradation products, CA 19-9, CA 125, and increasing circulating fibroblasts. On the other hand, genomic markers include peripheral blood gene expression profiles [9] and peripheral blood leukocyte telomere length [10].

Disease severity in IPF is assessed as illustrated in Table 1. 


\section{Cureus}

\begin{tabular}{|c|c|c|c|}
\hline & Mild disease & Moderate disease & Severe disease \\
\hline Symptoms and Signs & $\begin{array}{l}\text { Asymptomatic or mild, } \\
\text { nonproductive cough, and dyspnea } \\
\text { with substantial exertion }\end{array}$ & $\begin{array}{l}\text { Dyspnea on moderate } \\
\text { exertion, nonproductive } \\
\text { cough }\end{array}$ & $\begin{array}{l}\text { Dyspnea on mild } \\
\text { exertion (e.g., walking } \\
<300 \text { feet or climbing } \\
\text { more than one flight of } \\
\text { stairs) }\end{array}$ \\
\hline $\begin{array}{l}\text { Radiographic findings by high-resolution } \\
\text { computed tomography (HRCT) taken at three } \\
\text { levels (e.g., tracheal carina, inferior pulmonary } \\
\text { veins, and } 1 \mathrm{~cm} \text { above the dome of the } \\
\text { diaphragm) [1] }\end{array}$ & $\begin{array}{l}\text { Reticular opacities and areas of } \\
\text { honeycombing are limited to } \\
\text { subpleural and basilar areas, } \\
\text { involving less than } 10 \% \text { of the lung } \\
\text { parenchyma }\end{array}$ & $\begin{array}{l}\text { Reticular opacities involving } \\
20 \%-30 \% \text { of the lung and } \\
\text { honeycombing involving } \\
<5 \% \text { of the } \\
\text { parenchyma [11] }\end{array}$ & $\begin{array}{l}\text { Extensive } \\
\text { honeycombing is noted } \\
\text { ( }>5 \% \text { of the } \\
\text { parenchyma in three or } \\
\text { more zones) [11] }\end{array}$ \\
\hline Pulmonary function tests (PFTs) & $\begin{array}{l}\text { Normal or may show mild } \\
\text { reductions in forced vital capacity } \\
\text { (FVC), diffusing capacity (DLCO) }\end{array}$ & $\begin{array}{l}\text { Reduced FVC }(50 \%-70 \% \text { of } \\
\text { predicted), a reduced } \\
\text { DLCO }(45 \%-65 \% \text { of } \\
\text { predicted) }\end{array}$ & $\begin{array}{l}\text { Moderate to severe } \\
\text { reductions in the FVC } \\
\text { ( }<50 \% \text { of predicted), } \\
\text { DLCO ( }<50 \% \text { of } \\
\text { predicted) }\end{array}$ \\
\hline Six-minute walk test (6MWT) & Normal or mildly reduced & $\begin{array}{l}\text { Reduced and supplemental } \\
\text { oxygen may be needed with } \\
\text { exertion }\end{array}$ & $\begin{array}{l}\text { Desaturation }(\geq 4 \%) \\
\text { during the test }[12]\end{array}$ \\
\hline $\begin{array}{l}\text { Pulmonary alveolar to arterial oxygen gradient } \\
{\left[\mathrm{P}(\mathrm{A}-\mathrm{a}) \mathrm{O}_{2}\right]}\end{array}$ & $\begin{array}{l}\text { Normal or mildly elevated }(<20 \\
\mathrm{mmHg})\end{array}$ & Elevated $(21-30 \mathrm{mmHg}$ ) & elevated (>30 mmHg) \\
\hline
\end{tabular}

TABLE 1: Symptoms and signs, HRCT findings, PFTs, 6MWT, and $\mathrm{P}(\mathrm{A}-\mathrm{a}) \mathrm{O} 2$ gradient differences in IPF patients with different disease severities

PFTs, Pulmonary function tests; HRCT, high-resolution computed tomography; $6 \mathrm{MWT}$, six-minute walk test; $\mathrm{P}(\mathrm{A}-\mathrm{a}) \mathrm{O}_{2}$, pulmonary alveolar to arterial oxygen gradient; IPF, idiopathic pulmonary fibrosis.

\section{Medical therapies}

Until now, there is no curative treatment for IPF; however, nintedanib and pirfenidone are two medications working on slowing disease progression $[2,4,13]$ and do have a mortality benefit [14]. According to the current data, neither medication is superior in terms of efficacy; and thus, choosing between either of them will depend on the patient's tolerance to side effects. Table 2 demonstrates a detailed comparison between both medications. 


\section{Cureus}

Nintedanib

Tyrosine kinase receptor blocker preventing the release of fibrogenic growth

Mechanism of action and inhibitors.

Dose and administration $150 \mathrm{mg}$ every $12 \mathrm{hrs}$

\begin{abstract}
Adverse effects
\end{abstract}

Precautions to be taken

Efficacy

Decreased the pulmonary function decline and prolonged the time for first exacerbation per clinical trials mentioned below

No clinical trials were done on patients with severe disease, and only results of observational trials were reported. Reduction in pulmonary function decline was Role in severe noted. However, improvement in survival or symptoms was not disease evident $[22,23]$. Side effects were more evident with higher rates of treatment interruption [22,24].

\section{Pirfenidone}

Blocks transforming growth factor-beta (TGF- $\beta$ )-stimulated collagen synthesis and decreases the extracellular matrix [17,18]. Inhibits proliferation of fibroblasts.

$40 \mathrm{mg} / \mathrm{kg}$ per day and not exceeding 2403 mg per day in three divided doses. 1 capsule is $267 \mathrm{mg}$. Starting dose is 1 capsule TID for a week; then titrate it up to be 2 capsules TID for another week, and then titrate it up to full dose 3 capsules TID.

GIT upset including anorexia, dyspepsia, nausea, abdominal pain, and diarrhea [20]. Hepatotoxicity [20], Dry skin, itching, and hyperpigmentation.

Should be taken after meals to reduce GIT upset symptoms [21]. Liver function tests should be checked before starting treatment, then monthly for 6 months, and then every 3 months [20]. Pirfenidone is metabolized by CYP1A2, so any CYP1A2 inhibitors use should be associated with a reduction in the pirfenidone dose [20].

Decreases pulmonary function decline and has a mortality benefit in patients with mildto-moderate disease according to the clinical trials mentioned below.

Very limited clinical trials were done on patients with severe disease. RECAP study showed the same rate of decline in pulmonary function tests in both severe and non-severe disease patients. However, clinical worsening of IPF and treatment interruption were more common in severe disease than non-severe $[25,26]$.

ASCEND trial [32], CAPACITY 004, and 006 trials [33]

\section{TABLE 2: Comparison between nintedanib and pirfenidone}

\section{Supportive care}

Supportive care is crucial for IPF patients and considered one of the main lines of treatment in IPF. It can be categorized in the following main points:

Supplemental Oxygen

Long-term oxygen therapy (LTOT) is considered an inevitable treatment in patients with IPF with disease progression, either intermittently during exertion or sleep or continuously with severe disease. Indications for continuous LTOT depend on arterial oxygen tension $\left(\mathrm{PaO}_{2}\right)$ and pulse oxygen saturation $\left(\mathrm{SpO}_{2}\right)$ [34]. In general, $\mathrm{PaO}_{2}<56 \mathrm{mmHg}$ or $\mathrm{SpO}_{2}<89 \mathrm{mmHg}$ is an indication for continuous LTOT. However, in cases where there is presence of cor pulmonale, polycythemia, or right-sided heart failure, $\mathrm{PaO}_{2}<60 \mathrm{mmHg}$ or $\mathrm{SpO}_{2}<90$ $\mathrm{mmHg}$ is an indication for continuous LTOT. The LTOT may be indicated during sleep if the patient meets the above criteria or if $\mathrm{PaO}_{2}$ drops $>10 \mathrm{mmHg}$ and/or $\mathrm{SpO}_{2}$ drops $>5 \%$ with clinical evidence of nocturnal hypoxemia including insomnia, morning headaches, and impaired cognitive function. LTOT may be indicated during exercise if the patient meets the general indication of LTOT. Some studies showed that 
hyperoxia improves exercise tolerance in a dose-dependent manner, up to an inspired oxygen fraction of $50 \%$ [35], and thus, oxygen therapy may be indicated if the patient is having significant dyspnea during exercise even if the patient is not desaturating [36]. It is important to note, however, that oxygen is neither beneficial nor does it provide symptomatic relief as a palliative treatment in dyspnea without hypoxemia in patients with advanced lung diseases.

LTOT may improve quality of life, mental function, and exercise capacity. It can also reduce the frequency of hospitalization, cardiovascular complications, and mortality [37-39]. Most of the trials done to assess LTOT benefits were on COPD patients. More studies are needed to be applied to IPF patients.

While oxygen therapy is needed to correct hypoxemia, the oxygen flow rate should be accurately adjusted depending on $\mathrm{PaO}_{2}, \mathrm{SpO}_{2}$, and $\mathrm{PaCO}_{2}$ to maintain adequate acid-base status, which can be perfectly assessed through arterial blood gas measurements. Studies do not show an optimum level for $\mathrm{PaO}_{2}$ or $\mathrm{SpO}_{2}$, which can improve survival or quality of life. However, a $\mathrm{PaO}_{2}$ of $60-65 \mathrm{mmHg}$ or $\mathrm{SpO}_{2}$ of $90 \%-92 \%$ is generally considered an adequate range as hypoxemia is corrected without increasing the risk of $\mathrm{CO}_{2}$ retention [40]. Moreover, this range has the least risk for oxidative stress caused by the oxygen therapy, which in turn causes cell remodeling, cell death, and tissue damage [41].

\section{Pulmonary Rehabilitation}

Dyspnea on exertion and poor exercise tolerance are the main symptoms of IPF. Several studies have shown that pulmonary rehabilitation can ameliorate these symptoms leading to improvement in quality of life [4245].

Vaccination

Patients should be educated about the importance of vaccination against influenza and pneumonia as they decrease the risk and frequency of IPF exacerbations secondary to these infections. Influenza and pneumococcal polysaccharide vaccine should be offered to all IPF patients unless contraindicated.

\section{Education and Palliative Care}

Better outcomes were seen with patients who were educated about their diagnosis and management [46]. Palliative care discussion should be a part of the patient's education as it aims to relieve suffering at all stages of the disease and is not limited to the end of life care [47]. Understanding patient's beliefs and desires is crucial for goals of care [48].

\section{Lung transplantation}

IPF is the most common interstitial lung disease among referrals for lung transplantation [49]. Understanding the type of lung transplantation, timing and indication of referral, factors putting the patient at high risk for the procedure, and physiological changes occurring posttransplantation are all crucial for determining candidates for transplantation and a proper plan of management.

After transplantation, pulmonary function tests and oxygenation improve significantly as observed in the short- and long-term follow-up of the recipients [50].

Type of Transplantation Procedure

Single lung transplantation (SLT) is considered the standard procedure for IPF [49]. After SLT, the remaining native lung tissue with low lung compliance and high vascular resistance will divert the ventilation and perfusion to the normal transplanted lung tissue. Bilateral lung transplant (BLT) is preferred if lungs with IPF have developed cysts, bullae, and bronchiectasis, which can act as a nidus for infections in the transplanted lung in SLT. BLT has shown better long-term survival and higher forced expiratory volume in one second (FEV1) in some studies when compared to SLT [51,52]. Living donor lobar lung transplantation (LDLLT) can be considered as a lifesaving option for highly critical IPF patients who may die waiting for SLT. A study was done on nine patients having LDLLT, and only one patient passed away after two lobes transplants, whereas the other eight patients' survival was between 10 and 48 months after transplant [53].

Timing of Referral for Transplantation

IPF patients are usually the most critical patients on the transplant list with the highest death rate, that is why early referral for transplant evaluation should be done even before assessing response to initial medical treatment [54]. IPF patients should be referred for transplantation if they meet the following criteria [55] including dyspnea or functional disability related to lung disease and desaturating below $89 \%$ at 
rest or exertion. Moreover, diffusing capacity (DLCO) < 40\% of predicted, forced vital capacity (FVC) $<80 \%$ of predicted, and decline in FVC $\geqslant 5 \%-10 \%$ and DLCO $\geqslant 15 \%$ during six months of follow-up are the recommended spirometry criteria. Radiologically and histologically, a picture of usual interstitial pneumonia (UIP) is needed for referral.

Placing on Transplant List and Priority on the List

Patients are usually listed on the transplant list if they meet the following: [55] hospitalization due to respiratory decline or acute exacerbation, desaturating to $<88 \%$ or distance walked $<250$ meters or $>50$-meter decline in distance walked over six months. The decline in FVC $\geqslant 5 \%-10 \%$ and DLCO $\geqslant 15 \%$ during six months of follow-up are the required spirometry criteria. Furthermore, right heart catheterization or echocardiogram showing evidence of pulmonary hypertension is needed for the patient to be listed.

Priority on the list is determined using a lung allocation score that can assess the medical urgency and expected outcome on a scale from 1 to 100, where a higher score indicates higher urgency and better outcome with transplantation.

Factors Increasing the Risk of Transplantation

There are some factors that can put IPF patients at a higher risk of complications if they undergo lung transplants, which include pulmonary hypertension, telomerase complex mutations, and glucocorticoid therapy. Mild-to-moderate secondary pulmonary hypertension preoperatively has shown an increased risk of reperfusion injury. However, it did not show any worsening survival in two retrospective studies [52,56]. Telomerase complex mutations in IPF patients are usually associated with hematological complications including thrombocytopenia, anemia, neutropenia or severe bone marrow failure, and/or myelodysplasia with a high death rate $[57,58]$. Glucocorticoid therapy effect on lung transplantation differs according to the dose. Lower doses have not shown adverse outcomes, whereas higher doses may have lower survival after transplantation $[59,60]$.

\section{Future treatment}

Currently, there is no available curative treatment for IPF. All available treatments work for a subset of patients and have significant side effects, and survival is generally poor. There are some medications under trial, which seem to be less toxic and have promising outcomes.

Combination Nintedanib Plus Pirfenidone

As discussed above, each of these medications works on slowing down IPF progression. However, the efficacy of combining both medications is still under trial. Multiple trials were done by combining both medications together with different doses, and they were found to be safe and well-tolerated by the majority of patients without major adverse effects other than expected from either medication alone [61-63].

Pentraxin 2

Pentraxin 2 is a serum amyloid believed to have an antifibrotic and anti-inflammatory effect by inhibiting differentiation of monocytes into macrophages and fibrocytes, thus halting their profibrotic and proinflammatory effects. It also inhibits transforming growth factor (TGF)-beta1 production responsible for connective tissue formation. Pentraxin 2 serum level is found to be lower in IPF patients than in normal individuals [64]. The preliminary results for a randomized trial of IPF patients receiving recombinant human pentraxin 2 intravenous (IV) in comparison with placebo showed a slower decline in pulmonary function on the pentraxin 2 side [65].

GLPG1690

GLPG1690 is a potent and selective autotaxin inhibitor, which has a good safety and tolerability profile as it has the same adverse effects when compared to placebo in a small randomized clinical trial. However, larger randomized clinical trials are needed to determine its efficacy. Autotaxin is an enzyme responsible for the conversion of lysophospholipids (lysophosphatidic acid [LPA] from the hydrolysis of lysophosphatidic choline [LPC], the latter of which is produced in the liver). LPA is believed to stimulate dendritic cell differentiation and smooth muscle contraction and prevents apoptosis. Autotaxin may in part be responsible for the "chronic wound response." Little is known about the expression and function of autotaxin, LPA, and LPC in human diseases such as pulmonary fibrosis [66].

Pamrevlumab (FG-3019)

Pamrevlumab is a monoclonal antibody targeting connective tissue growth factor, which has a role in fibrosis pathogenesis. Studies have shown that it has a good safety profile, and it slows the decline in FVC 
compared with pirfenidone and nintedanib. It may become a potential IPF treatment [67]. Further larger trials are needed.

Treatment for Gastroesophageal Reflux Disease

Gastroesophageal reflux disease (GERD) is a common cause of chronic cough in the general population, but it is also found to be more common in IPF patients [68,69]. Moreover, in the presence of possibility of microaspiration with GERD, some studies hypothesized GERD as an important risk factor for the development or worsening of IPF [70-72] and the associated cough [73]. According to this hypothesis, several studies were done to monitor the effect of anti-GERD medications and surgery on progression and outcomes of IPF.

Upon using anti-GERD medications, some studies have shown decreased radiographic fibrosis scores on chest CT scans and better survival rates [74], while others showed a smaller decline in pulmonary function tests [75]. Some observational studies have shown a reduction in IPF-related mortality but not overall mortality [76].

Studies done on IPF patients after anti-reflux surgery showed it to be a well-tolerable procedure. Larger randomized trials are needed for the efficacy of the procedure on IPF progression [77].

\section{Medications that should not be used anymore}

The following are medications that were used in the past, but studies have recommended against using them either because of no benefit or severe side effects including higher mortality.

\section{Anticoagulation}

Anticoagulation with warfarin was previously used in IPF patients due to the assumption of the existence of prothrombotic state [78] and was found to improve mortality after three years follow-up when used with prednisone in comparison to prednisone alone in a non-blinded trial [79]. However, the Anticoagulant Effectiveness in Idiopathic Pulmonary Fibrosis trial (ACE-IPF) results showed increased mortality in patients on anticoagulation for IPF without other indications for anticoagulation, and thus, anticoagulation should not be used in IPF unless there is another indication for it [4].

\section{$N$-Acetylcysteine in Combination With Either Azathioprine-Prednisone or With Pirfenidone}

Azathioprine-prednisone in combination with $\mathrm{N}$-acetylcysteine or even $\mathrm{N}$-acetylcysteine as a monotherapy has been used for many years as it was supposed to have some benefit according to the preliminary results of IFIGENIA (Idiopathic Pulmonary Fibrosis International Group Exploring (N) acetylcysteine I Annual) trial [80]. However, PANTHER trial results showed more frequent hospitalizations and adverse effects including higher mortality with this combination therapy in comparison to placebo. We recommend against using this combination treatment [81]. Moreover, a recent study has shown that combination treatment with inhaled N-acetylcysteine and pirfenidone is likely to result in worse outcomes for IPF [82].

Endothelin Receptor Antagonists

Several trials were done on endothelin receptor antagonists to check their efficacy in IPF treatment, but they did not show any significant benefit, and sometimes they were even harmful to the patient. Bosentan was used in IPF for its anti-fibrotic properties, but it did not show any improvement in exercise tolerance or quality of life according to BUILD 1 trial (Efficacy and Safety of Oral Bosentan in Patients With Idiopathic Pulmonary Fibrosis) [83] or any improvement in mortality or frequency of exacerbations according to BUILD 3 trial (Bosentan Use in Interstitial Lung Disease 3) [84]. Macitentan was also used in IPF treatment in MUSIC trial (Macitentan Use in an IPF Clinical Study), which also did not show any significant benefits [85]. Ambrisentan was tested in ARTEMIS-IPF trial for the treatment of IPF, which did not show any benefit but instead showed more frequent hospitalizations and exacerbations in comparison to placebo [86].

Phosphodiesterase Inhibitors

Trials of sildenafil in patients with IPF for improving exercise tolerance and quality of life have shown minimal benefit $[87,88]$, so sildenafil is not advised for routine use in IPF.

\section{Methotrexate}

Methotrexate use did not show any benefit in the treatment of IPF, but instead, sometimes it induced pneumonitis that cannot be differentiated from an IPF exacerbation. However, methotrexate may be of benefit if IPF resulted from an autoimmune disease that can be treated with methotrexate, for example, as in rheumatoid arthritis [89]. 
Colchicine [90-92], cyclophosphamide [93], cyclosporine [94], etanercept [95], interferon gamma-1b [96], penicillamine [92], and simtuzumab [97] were studied separately in multiple studies, but none of them showed significant benefit or improvement in outcome. Therefore none of the aforementioned medications are recommended for the treatment of IPF.

\section{Conclusions}

This is a review of literature on the treatment options of stable IPF. We discussed the different severities and prognosis of IPF according to the clinical picture, radiographic findings, PFTs, 6 MWT, and P(A-a)O2. Nintedanib and pirfenidone are two medications that work on slowing disease progression and having a mortality benefit. However, supportive care is crucial for IPF patients and considered one of the main lines of treatment in IPF including supplemental oxygen, pulmonary rehabilitation, vaccination, patients' education, and palliative care discussions. IPF is the most common interstitial lung disease among referrals for lung transplantation. These patients are usually the most critical patients on the transplant list with the highest death rate. However, they need to fulfill certain criteria for lung transplantation referral and listing on priority list. Currently, there is no available curative treatment for IPF. There are some medications under trial, which seem to be less toxic and have promising outcomes including combination nintedanib plus pirfenidone, treatment for GERD, Pentraxin 2, and others. Some other medications were used before, but studies have recommended against them either due to no benefit or severe side effects including higher mortality. These therapies include anticoagulation, azathioprine-prednisone- $\mathrm{N}$-acetylcysteine, endothelin receptor antagonists, phosphodiesterase inhibitors, methotrexate, and others.

\section{Additional Information}

\section{Disclosures}

Conflicts of interest: In compliance with the ICMJE uniform disclosure form, all authors declare the following: Payment/services info: All authors have declared that no financial support was received from any organization for the submitted work. Financial relationships: All authors have declared that they have no financial relationships at present or within the previous three years with any organizations that might have an interest in the submitted work. Other relationships: All authors have declared that there are no other relationships or activities that could appear to have influenced the submitted work.

\section{Acknowledgements}

This research was supported (in whole or in part) by HCA and/or an HCA-affiliated entity. The views expressed in this publication represent those of the author(s) and do not necessarily represent the official views of HCA or any of its affiliated entities.

\section{References}

1. Lynch DA, Godwin JD, Safrin S, et al.: High-resolution computed tomography in idiopathic pulmonary fibrosis: diagnosis and prognosis. Am J Respir Crit Care Med. 2005, 172:488-93. 10.1164/rccm.200412$17560 \mathrm{C}$

2. Raghu G, Collard HR, Egan JJ, et al.: An official ATS/ERS/JRS/ALAT statement: idiopathic pulmonary fibrosis: evidence-based guidelines for diagnosis and management. Am J Respir Crit Care Med. 2011, 183:788-824. 10.1164/rccm.2009-040GL

3. King TE Jr, Pardo A, Selman M: Idiopathic pulmonary fibrosis. Lancet. 2011, 378:1949-61. 10.1016/S01406736(11)60052-4

4. Raghu G, Rochwerg B, Zhang Y, et al.: An official ATS/ERS/JRS/ALAT clinical practice guideline: treatment of idiopathic pulmonary fibrosis. An update of the 2011 clinical practice guideline. Am J Respir Crit Care Med. 2015, 192:e3-19. 10.1164/rccm.201506-1063ST

5. Ley B, Ryerson CJ, Vittinghoff E, et al.: A multidimensional index and staging system for idiopathic pulmonary fibrosis. Ann Intern Med. 2012, 156:684-91. 10.7326/0003-4819-156-10-201205150-00004

6. Durheim MT, Collard HR, Roberts RS, et al.: Association of hospital admission and forced vital capacity endpoints with survival in patients with idiopathic pulmonary fibrosis: analysis of a pooled cohort from three clinical trials. Lancet Respir Med. 2015, 3:388-96. 10.1016/S2213-2600(15)00093-4

7. Paterniti MO, Bi Y, Rekić D, Wang Y, Karimi-Shah BA, Chowdhury BA: Acute exacerbation and decline in forced vital capacity are associated with increased mortality in idiopathic pulmonary fibrosis. Ann Am Thorac Soc. 2017, 14:1395-402. 10.1513/AnnalsATS.201606-4580C

8. Ley B, Brown KK, Collard HR: Molecular biomarkers in idiopathic pulmonary fibrosis. Am J Physiol Lung Cell Mol Physiol. 2014, 307:L681-91. 10.1152/ajplung.00014.2014

9. Herazo-Maya JD, Noth I, Duncan SR, et al.: Peripheral blood mononuclear cell gene expression profiles predict poor outcome in idiopathic pulmonary fibrosis. Sci Transl Med. 2013, 5:205ra136. 10.1126/scitranslmed.3005964

10. Stuart BD, Lee JS, Kozlitina J, et al.: Effect of telomere length on survival in patients with idiopathic pulmonary fibrosis: an observational cohort study with independent validation. Lancet Respir Med. 2014, 2:557-65. 10.1016/S2213-2600(14)70124-9

11. Arakawa H, Honma K: Honeycomb lung: history and current concepts. AJR Am J Roentgenol. 2011, 196:77382. 10.2214/AJR.10.4873

12. Lama VN, Flaherty KR, Toews GB, et al.: Prognostic value of desaturation during a 6-minute walk test in idiopathic interstitial pneumonia. Am J Respir Crit Care Med. 2003, 168:1084-90. 10.1164/rccm.200302- 
2190C

13. Carlos WG, Strek ME, Wang TS, Patel H, Raghu G, Wilson KC, Thomson CC: Treatment of idiopathic pulmonary fibrosis. Ann Am Thorac Soc. 2016, 13:115-7. 10.1513/AnnalsATS.201510-713CME

14. Canestaro WJ, Forrester SH, Raghu G, Ho L, Devine BE: Drug treatment of idiopathic pulmonary fibrosis: systematic review and network meta-analysis. Chest. 2016, 149:756-66. 10.1016/j.chest.2015.11.013

15. Wollin L, Wex E, Pautsch A, Schnapp G, Hostettler KE, Stowasser S, Kolb M: Mode of action of nintedanib in the treatment of idiopathic pulmonary fibrosis. Eur Respir J. 2015, 45:1434-45. 10.1183/09031936.00174914

16. Richeldi L, du Bois RM, Raghu G, et al.: Efficacy and safety of nintedanib in idiopathic pulmonary fibrosis . N Engl J Med. 2014, 370:2071-82. 10.1056/NEJMoa1402584

17. Hunninghake GW, Kalica AR: Approaches to the treatment of pulmonary fibrosis. Am J Respir Crit Care Med. 1995, 151:915-8. 10.1164/ajrccm.151.3.7881692

18. Scotton CJ, Chambers RC: Molecular targets in pulmonary fibrosis: the myofibroblast in focus . Chest. 2007, 132:1311-21. 10.1378/chest.06-2568

19. Nintedanib. (2014). Accessed: November 10,2020: https://pubchem.ncbi.nlm.nih.gov/compound/Nintedanib.

20. LABEL: ESBRIET- pirfenidone capsule. (2019). Accessed: August 12, 2019: https://dailymed.nlm.nih.gov/dailymed/drugInfo.cfm?setid=0ab861c2-d5ca-4f92-854c-6477971a1b38.

21. Valeyre D, Albera C, Bradford WZ, et al.: Comprehensive assessment of the long-term safety of pirfenidone in patients with idiopathic pulmonary fibrosis. Respirology. 2014, 19:740-7. 10.1111/resp.12297

22. Harari S, Caminati A, Poletti V, et al.: A real-life multicenter national study on nintedanib in severe idiopathic pulmonary fibrosis. Respiration. 2018, 95:433-40. 10.1159/000487711

23. Yoon HY, Park S, Kim DS, Song JW: Efficacy and safety of nintedanib in advanced idiopathic pulmonary fibrosis. Respir Res. 2018, 19:203. 10.1186/s12931-018-0907-8

24. Bonella F, Kreuter M, Hagmeyer L, et al.: Insights from the German compassionate use program of nintedanib for the treatment of idiopathic pulmonary fibrosis. Respiration. 2016, 92:98-106. $10.1159 / 000448288$

25. Highlights of prescribing information for Esbriet (pirfenidone) . (2019). Accessed: August 12, 2019: https://www.accessdata.fda.gov/drugsatfda_docs/label/2019/022535s012,208780s002lbl.pdf.

26. Costabel U, Albera C, Glassberg MK, et al.: Effect of pirfenidone in patients with more advanced idiopathic pulmonary fibrosis. Respir Res. 2019, 20:55. 10.1186/s12931-019-1021-2

27. Richeldi L, Costabel U, Selman M, et al.: Efficacy of a tyrosine kinase inhibitor in idiopathic pulmonary fibrosis. N Engl J Med. 2011, 365:1079-87. 10.1056/NEJMoa1103690

28. Richeldi L, Kreuter M, Selman M, et al.: Long-term treatment of patients with idiopathic pulmonary fibrosis with nintedanib: results from the TOMORROW trial and its open-label extension. Thorax. 2018, 73:581-3. 10.1136/thoraxjnl-2016-209701

29. Costabel U, Inoue Y, Richeldi L, Collard HR, Tschoepe I, Stowasser S, Azuma A: Efficacy of nintedanib in idiopathic pulmonary fibrosis across prespecified subgroups in INPULSIS. Am J Respir Crit Care Med. 2016, 193:178-85. 10.1164/rccm.201503-05620C

30. Richeldi L, Cottin V, du Bois RM, et al.: Nintedanib in patients with idiopathic pulmonary fibrosis: combined evidence from the TOMORROW and INPULSIS $\left({ }^{\circledR}\right)$ trials. Respir Med. 2016, 113:74-9. 10.1016/j.rmed.2016.02.001

31. Flaherty KR, Kolb M, Vancheri C, Tang W, Conoscenti CS, Richeldi L: Stability or improvement in forced vital capacity with nintedanib in patients with idiopathic pulmonary fibrosis. Eur Respir J. 2018, 52:1702593. 10.1183/13993003.02593-2017

32. King TE Jr, Bradford WZ, Castro-Bernardini S, et al.: A phase 3 trial of pirfenidone in patients with idiopathic pulmonary fibrosis. N Engl J Med. 2014, 370:2083-92. 10.1056/NEJMoa1402582

33. Noble PW, Albera C, Bradford WZ, et al.: Pirfenidone in patients with idiopathic pulmonary fibrosis (CAPACITY): two randomised trials. Lancet. 2011, 377:1760-9. 10.1016/S0140-6736(11)60405-4

34. Lacasse Y, Tan AM, Maltais F, Krishnan JA: Home oxygen in chronic obstructive pulmonary disease . Am J Respir Crit Care Med. 2018, 197:1254-6. 10.1164/rccm.201802-0382CI

35. Somfay A, Porszasz J, Lee SM, Casaburi R: Dose-response effect of oxygen on hyperinflation and exercise endurance in nonhypoxaemic COPD patients. Eur Respir J. 2001, 18:77-84. 10.1183/09031936.01.00082201

36. Snider GL: Enhancement of exercise performance in COPD patients by hyperoxia: a call for research . Chest. 2002, 122:1830-6. 10.1378/chest.122.5.1830

37. Eaton T, Lewis C, Young P, Kennedy Y, Garrett JE, Kolbe J: Long-term oxygen therapy improves healthrelated quality of life. Respir Med. 2004, 98:285-93. 10.1016/j.rmed.2003.10.008

38. Stewart BN, Hood CI, Block AJ: Long-term results of continuous oxygen therapy at sea level . Chest. 1975, 68:486-92. 10.1378/chest.68.4.486

39. Tanni SE, Vale SA, Lopes PS, Guiotoko MM, Godoy I, Godoy I: Influence of the oxygen delivery system on the quality of life of patients with chronic hypoxemia. J Bras Pneumol. 2007, 33:161-7. 10.1590/s180637132007000200010

40. Siemieniuk RAC, Chu DK, Kim LH, et al.: Oxygen therapy for acutely ill medical patients: a clinical practice guideline. BMJ. 2018, 363:k4169. 10.1136/bmj.k4169

41. Sjöberg F, Singer M: The medical use of oxygen: a time for critical reappraisal . J Intern Med. 2013, 274:50528. 10.1111/joim.12139

42. Dowman L, Hill CJ, Holland AE: Pulmonary rehabilitation for interstitial lung disease . Cochrane Database Syst Rev. 2014, CD006322. 10.1002/14651858.CD006322.pub3

43. Vainshelboim B, Oliveira J, Yehoshua L, Weiss I, Fox BD, Fruchter O, Kramer MR: Exercise training-based pulmonary rehabilitation program is clinically beneficial for idiopathic pulmonary fibrosis. Respiration. 2014, 88:378-88. 10.1159/000367899

44. Holland AE, Hill CJ, Conron M, Munro P, McDonald CF: Short term improvement in exercise capacity and symptoms following exercise training in interstitial lung disease. Thorax. 2008, 63:549-54. 10.1136/thx.2007.088070

45. Ferreira A, Garvey C, Connors GL, et al.: Pulmonary rehabilitation in interstitial lung disease: benefits and 
predictors of response. Chest. 2009, 135:442-7. 10.1378/chest.08-1458

46. Collard HR, Tino G, Noble PW, Shreve MA, Michaels M, Carlson B, Schwarz MI: Patient experiences with pulmonary fibrosis. Respir Med. 2007, 101:1350-4. 10.1016/j.rmed.2006.10.002

47. Liang Z, Hoffman LA, Nouraie M, et al.: Referral to palliative care infrequent in patients with idiopathic pulmonary fibrosis admitted to an intensive care unit. J Palliat Med. 2017, 20:134-40. 10.1089/jpm.2016.0258

48. Daniels CE, Ryu JH: Treatment of idiopathic pulmonary fibrosis. Semin Respir Crit Care Med. 2006, 27:66876. $10.1055 / \mathrm{s}-2006-957338$

49. International Thoracic Organ Transplant (TTX) Registry Data Slides . (2020). Accessed: July 21, 2020: https://ishltregistries.org/registries/slides.asp.

50. Meyers BF, Lynch JP, Trulock EP, Guthrie T, Cooper JD, Patterson GA: Single versus bilateral lung transplantation for idiopathic pulmonary fibrosis: a ten-year institutional experience. J Thorac Cardiovasc Surg. 2000, 120:99-107. 10.1067/mtc.2000.106322

51. Neurohr C, Huppmann P, Thum D, et al.: Potential functional and survival benefit of double over single lung transplantation for selected patients with idiopathic pulmonary fibrosis. Transpl Int. 2010, 23:887-96. 10.1111/j.1432-2277.2010.01071.x

52. Spratt JR, Tomic R, Brown RZ, et al.: Single versus bilateral lung transplantation for idiopathic pulmonary fibrosis in the lung allocation score era. J Surg Res. 2019, 234:84-95. 10.1016/j.jss.2018.08.054

53. Date H, Tanimoto Y, Goto K, Yamadori I, Aoe M, Sano Y, Shimizu N: A new treatment strategy for advanced idiopathic interstitial pneumonia: living-donor lobar lung transplantation. Chest. 2005, 128:1364-70. 10.1378/chest.128.3.1364

54. Glanville AR: COUNTERPOINT: should every patient with idiopathic pulmonary fibrosis be referred for transplant evaluation? No. Chest. 2020, 157:1413-4. 10.1016/j.chest.2019.12.031

55. Weill D, Benden C, Corris PA, et al.: A consensus document for the selection of lung transplant candidates: 2014--an update from the pulmonary transplantation council of the international society for heart and lung transplantation. J Heart Lung Transplant. 2015, 34:1-15. 10.1016/j.healun.2014.06.014

56. Fitton TP, Kosowski TR, Barreiro CJ, et al.: Impact of secondary pulmonary hypertension on lung transplant outcome. J Heart Lung Transplant. 2005, 24:1254-9. 10.1016/j.healun.2004.08.009

57. Borie R, Kannengiesser C, Hirschi S, et al.: Severe hematologic complications after lung transplantation in patients with telomerase complex mutations. J Heart Lung Transplant. 2015, 34:538-46. 10.1016/i.healun.2014.11.010

58. Silhan LL, Shah PD, Chambers DC, et al.: Lung transplantation in telomerase mutation carriers with pulmonary fibrosis. Eur Respir J. 2014, 44:178-87. 10.1183/09031936.00060014

59. Park SJ, Nguyen DQ, Savik K, Hertz MI, Bolman RM 3rd: Pre-transplant corticosteroid use and outcome in lung transplantation. J Heart Lung Transplant. 2001, 20:304-9. 10.1016/s1053-2498(00)00316-8

60. McAnally KJ, Valentine VG, LaPlace SG, McFadden PM, Seoane L, Taylor DE: Effect of pre-transplantation prednisone on survival after lung transplantation. J Heart Lung Transplant. 2006, 25:67-74. 10.1016/i.healun.2005.07.012

61. Vancheri C, Kreuter M, Richeldi L, et al.: Nintedanib with add-on pirfenidone in idiopathic pulmonary fibrosis. Results of the INJOURNEY trial. Am J Respir Crit Care Med. 2018, 197:356-63.

10.1164/rccm.201706-13010C

62. Ogura T, Taniguchi H, Azuma A, et al.: Safety and pharmacokinetics of nintedanib and pirfenidone in idiopathic pulmonary fibrosis. Eur Respir J. 2015, 45:1382-92. 10.1183/09031936.00198013

63. Flaherty KR, Fell CD, Huggins JT, et al.: Safety of nintedanib added to pirfenidone treatment for idiopathic pulmonary fibrosis. Eur Respir J. 2018, 52:1800230. 10.1183/13993003.00230-2018

64. Murray LA, Chen Q, Kramer MS, et al.: TGF-beta driven lung fibrosis is macrophage dependent and blocked by serum amyloid P. Int J Biochem Cell Biol. 2011, 43:154-62. 10.1016/j.biocel.2010.10.013

65. Raghu G, van den Blink B, Hamblin MJ, et al.: Effect of recombinant human pentraxin 2 vs placebo on change in forced vital capacity in patients with idiopathic pulmonary fibrosis: a randomized clinical trial. JAMA. 2018, 319:2299-307. 10.1001/jama.2018.6129

66. Maher TM, van der Aar EM, Van de Steen O, et al.: Safety, tolerability, pharmacokinetics, and pharmacodynamics of GLPG1690, a novel autotaxin inhibitor, to treat idiopathic pulmonary fibrosis (FLORA): a phase 2a randomised placebo-controlled trial. Lancet Respir Med. 2018, 6:627-35. 10.1016/S2213-2600(18)30181-4

67. Di Martino E, Provenzani A, Vitulo P, Polidori P: Systematic review and meta-analysis of pirfenidone, nintedanib, and pamrevlumab for the treatment of idiopathic pulmonary fibrosis. Ann Pharmacother. 2021, 55:723-31. 10.1177/1060028020964451

68. Tobin RW, Pope CE 2nd, Pellegrini CA, Emond MJ, Sillery J, Raghu G: Increased prevalence of gastroesophageal reflux in patients with idiopathic pulmonary fibrosis. Am J Respir Crit Care Med. 1998, 158:1804-8. 10.1164/ajrccm.158.6.9804105

69. Raghu G, Freudenberger TD, Yang S, et al.: High prevalence of abnormal acid gastro-oesophageal reflux in idiopathic pulmonary fibrosis. Eur Respir J. 2006, 27:136-42. 10.1183/09031936.06.00037005

70. Schachter LM, Dixon J, Pierce RJ, O'Brien P: Severe gastroesophageal reflux is associated with reduced carbon monoxide diffusing capacity. Chest. 2003, 123:1932-8. 10.1378/chest.123.6.1932

71. Lee IS, Collard HR, Raghu G, et al.: Does chronic microaspiration cause idiopathic pulmonary fibrosis? Am J Med. 2010, 123:304-11. 10.1016/j.amjmed.2009.07.033

72. Pashinsky YY, Jaffin BW, Litle VR: Gastroesophageal reflux disease and idiopathic pulmonary fibrosis. Mt Sinai J Med. 2009, 76:24-9. 10.1002/msj.20088

73. Dutta P, Funston W, Mossop H, et al.: Randomised, double-blind, placebo-controlled pilot trial of omeprazole in idiopathic pulmonary fibrosis. Thorax. 2019, 74:346-53. 10.1136/thoraxjnl-2018-212102

74. Lee JS, Ryu JH, Elicker BM, et al.: Gastroesophageal reflux therapy is associated with longer survival in patients with idiopathic pulmonary fibrosis. Am J Respir Crit Care Med. 2011, 184:1390-4. 10.1164/rccm.201101-01380C

75. Lee JS, Collard HR, Anstrom KJ, et al.: Anti-acid treatment and disease progression in idiopathic pulmonary 
fibrosis: an analysis of data from three randomised controlled trials. Lancet Respir Med. 2013, 1:369-76. 10.1016/S2213-2600(13)70105-X

76. Fidler L, Sitzer N, Shapera S, Shah PS: Treatment of gastroesophageal reflux in patients with idiopathic pulmonary fibrosis: a systematic review and meta-analysis. Chest. 2018, 153:1405-1.

10.1016/j.chest.2018.03.008

77. Raghu G, Pellegrini CA, Yow E, et al.: Laparoscopic anti-reflux surgery for the treatment of idiopathic pulmonary fibrosis (WRAP-IPF): a multicentre, randomised, controlled phase 2 trial. Lancet Respir Med. 2018, 6:707-14. 10.1016/S2213-2600(18)30301-1

78. Sode BF, Dahl M, Nielsen SF, Nordestgaard BG: Venous thromboembolism and risk of idiopathic interstitial pneumonia: a nationwide study. Am J Respir Crit Care Med. 2010, 181:1085-92. 10.1164/rccm.200912$19510 \mathrm{C}$

79. Kubo H, Nakayama K, Yanai M, Suzuki T, Yamaya M, Watanabe M, Sasaki H: Anticoagulant therapy for idiopathic pulmonary fibrosis. Chest. 2005, 128:1475-82. 10.1378/chest.128.3.1475

80. Demedts M, Behr J, Buhl R, et al.: High-dose acetylcysteine in idiopathic pulmonary fibrosis. N Engl J Med. 2005, 353:2229-42. 10.1056/NEJMoa042976

81. Idiopathic Pulmonary Fibrosis Clinical Research Network, Raghu G, Anstrom KJ, King TE Jr, Lasky JA, Martinez FJ: Prednisone, azathioprine, and N-acetylcysteine for pulmonary fibrosis. N Engl J Med. 2012, 366:1968-77. 10.1056/NEJMoa1113354

82. Sakamoto S, Kataoka K, Kondoh Y, et al.: Pirfenidone plus inhaled N-acetylcysteine for idiopathic pulmonary fibrosis: a randomised trial. Eur Respir J. 2021, 57:2000348. 10.1183/13993003.00348-2020

83. King TE Jr, Behr J, Brown KK, et al.: BUILD-1: a randomized placebo-controlled trial of bosentan in idiopathic pulmonary fibrosis. Am J Respir Crit Care Med. 2008, 177:75-81. 10.1164/rccm.200705-7320C

84. King TE Jr, Brown KK, Raghu G, et al.: BUILD-3: a randomized, controlled trial of bosentan in idiopathic pulmonary fibrosis. Am J Respir Crit Care Med. 2011, 184:92-9. 10.1164/rccm.201011-18740C

85. Raghu G, Million-Rousseau R, Morganti A, Perchenet L, Behr J: Macitentan for the treatment of idiopathic pulmonary fibrosis: the randomised controlled MUSIC trial. Eur Respir J. 2013, 42:1622-32. 10.1183/09031936.00104612

86. Raghu G, Behr J, Brown KK, et al.: Treatment of idiopathic pulmonary fibrosis with ambrisentan: a parallel, randomized trial. Ann Intern Med. 2013, 158:641-9. 10.7326/0003-4819-158-9-201305070-00003

87. Kolb M, Raghu G, Wells AU, et al.: Nintedanib plus sildenafil in patients with idiopathic pulmonary fibrosis . N Engl J Med. 2018, 379:1722-31. 10.1056/NEJMoa1811737

88. Behr J, Kolb M, Song JW, et al.: Nintedanib and sildenafil in patients with idiopathic pulmonary fibrosis and right heart dysfunction. A prespecified subgroup analysis of a double-blind randomized clinical trial (INSTAGE). Am J Respir Crit Care Med. 2019, 200:1505-12. 10.1164/rccm.201903-04880C

89. Scott DG, Bacon PA: Response to methotrexate in fibrosing alveolitis associated with connective tissue disease. Thorax. 1980, 35:725-31. 10.1136/thx.35.10.725

90. Douglas WW, Ryu JH, Bjoraker JA, et al.: Colchicine versus prednisone as treatment of usual interstitial pneumonia. Mayo Clin Proc. 1997, 72:201-9. 10.4065/72.3.201

91. Douglas WW, Ryu JH, Swensen SJ, Offord KP, Schroeder DR, Caron GM, DeRemee RA: Colchicine versus prednisone in the treatment of idiopathic pulmonary fibrosis. A randomized prospective study. Members of the lung study group. Am J Respir Crit Care Med. 1998, 158:220-5. 10.1164/ajrccm.158.1.9709089

92. Selman M, Carrillo G, Salas J, Padilla RP, Pérez-Chavira R, Sansores R, Chapela R: Colchicine, Dpenicillamine, and prednisone in the treatment of idiopathic pulmonary fibrosis: a controlled clinical trial. Chest. 1998, 114:507-12. 10.1378/chest.114.2.507

93. Collard HR, Ryu JH, Douglas WW, Schwarz MI, Curran-Everett D, King TE Jr, Brown KK: Combined corticosteroid and cyclophosphamide therapy does not alter survival in idiopathic pulmonary fibrosis. Chest. 2004, 125:2169-74. 10.1378/chest.125.6.2169

94. Moolman JA, Bardin PG, Rossouw DJ, Joubert JR: Cyclosporin as a treatment for interstitial lung disease of unknown aetiology. Thorax. 1991, 46:592-5. 10.1136/thx.46.8.592

95. Raghu G, Brown KK, Costabel U, et al.: Treatment of idiopathic pulmonary fibrosis with etanercept: an exploratory, placebo-controlled trial. Am J Respir Crit Care Med. 2008, 178:948-55. 10.1164/rccm.200709$14460 \mathrm{C}$

96. King TE Jr, Albera C, Bradford WZ, et al.: Effect of interferon gamma-1b on survival in patients with idiopathic pulmonary fibrosis (INSPIRE): a multicentre, randomised, placebo-controlled trial. Lancet. 2009, 374:222-8. 10.1016/S0140-6736(09)60551-1

97. Raghu G, Brown KK, Collard HR, et al.: Efficacy of simtuzumab versus placebo in patients with idiopathic pulmonary fibrosis: a randomised, double-blind, controlled, phase 2 trial. Lancet Respir Med. 2017, 5:22-3. 10.1016/S2213-2600(16)30421-0 